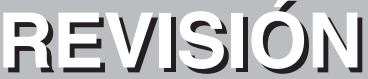

\section{Action and fate of natural and synthetic antioxidants during frying}

\author{
By S. Marmesat, A. Morales, J. Velasco and M.C. Dobarganes \\ Instituto de la Grasa (CSIC). Avda. Padre García Tejero, 4. 41012- Sevilla \\ ( ${ }^{\star}$ Corresponding author: cdobar@ cica.es)
}

\section{RESUMEN}

Acción y destino de los antioxidantes naturales y sintéticos durante el proceso de fritura.

La acción de antioxidantes para retrasar la oxidación en grasas y aceites es bien conocida aunque la mayor parte de la información está relacionada con su actividad a temperatura ambiente durante el almacenamiento o a las temperaturas moderadas de los ensayos de oxidación acelerada. Sin embargo, su efectividad a la temperatura elevada de procesos como la fritura es más compleja debido a la existencia de reacciones oxidativas y térmicas que tienen lugar simultáneamente. En esta revisión, se resumen los estudios principales que definen la acción de los antioxidantes naturales y sintéticos durante el proceso de fritura. Se ha dividido en dos partes que resumen la acción y los compuestos de degradación de los antioxidantes naturales, es decir, tocoferoles y otros compuestos fenólicos presentes en aceites de oliva, sésamo y salvado de arroz, y de los principales antioxidantes sintéticos como BHA, BHT y TBHQ.

PALABRAS CLAVE: Antioxidantes sintéticos - BHA BHT - Compuestos fenólicos - Fritura - TBHQ - Tocoferoles.

\section{SUMMARY}

Action and fate of natural and synthetic antioxidants during frying.

The action of antioxidants to delay lipid oxidation in fats and oils is well known although most of the information is related to their effects at room temperature during storage or at the moderate temperatures of the accelerated tests to measure oil stability. However, oxidation at the high temperatures of food processes like frying, is more complex because the availability of air is unknown and both oxidative and thermal reactions are simultaneously involved. In this review, the main studies defining the action of natural and synthetic antioxidants at frying temperatures are summarized. This review has been divided into two main parts concerning the information on natural antioxidants, i.e. tocopherols and other phenolic compounds present in specific oils like olive, sesame and rice bran oils, and on synthetic antioxidants, i.e. BHA, $\mathrm{BHT}$ and $\mathrm{TBHQ}$.

KEY-WORDS: BHA-BHT-Frying - Phenolic compounds - Synthetic antioxidants - TBHQ - Tocopherols.

\section{INTRODUCTION}

The action of antioxidants to delay lipid oxidation in fats and oils is well known although most of the information is related to their effects at room temperature during storage or at the moderate temperatures of accelerated tests. At room or moderate temperatures, autoxidation reactions taking place through chain reactions of free radicals are relatively slow; the hydroperoxides are the major products formed and their concentration increases until advanced stages of oxidation. Under these conditions, the activity of primary antioxidants is due to their ability to donate a hydrogen to the lipid free radicals preventing a new lipid molecule from entering in the chain to be oxidized. However, oxidation at the high temperatures of food processes like frying is far more complex because both oxidative and thermal reactions are simultaneously involved. At high temperatures, the formation of new compounds is very rapid, the oxygen pressure is reduced, and the hydroperoxides decompose rapidly and are practically absent above $150^{\circ} \mathrm{C}$, indicating that the decomposition of hydroperoxides becomes faster than their formation (Dobarganes, 1998). As a result, dimeric and oligomeric triglycerides form from the very early stages of heating and a significant part of the new compounds formed are non-oxygenated compounds due to the combination of two variables: high temperature and low oxygen pressure (Dobarganes and Márquez-Ruiz, 2007).

The information on the fate of antioxidants at frying temperatures is limited. Chemical degradation of antioxidants seems to be the major pathway for antioxidant loss at high temperatures although volatilization and steam distillation due to both the high temperature and the large amount of steam water escaping from the food have also been postulated.

In this review, the main studies on the action of antioxidants in the frying process and on their degradation compounds formed are evaluated. This review has been divided into two main parts concerning the information on natural and synthetic antioxidants 


\section{NATURAL ANTIOXIDANTS}

\subsection{Tocopherols and tocotrienols}

The protection of tocopherols at the high temperatures of the frying process has been demonstrated by comparing the formation of new compounds in natural oils and tocopherol-stripped oils. For oils of different degrees of unsaturation, the degradation was significantly higher when the tocopherols were absent although their activity seemed to be more related to the type of natural tocopherols present in the oil than to the degree of oil unsaturation (Barrera Arellano et al., 2002). However, at low temperatures and at temperatures used in oxidative accelerated tests $\left(100-120^{\circ} \mathrm{C}\right)$, the loss in tocopherols clearly depended on the degree of unsaturation (Yuki and Ishikawa 1976; MartinPolvillo et al., 2004; Márquez-Ruiz et al., 2008). Thus, a mechanism dependent on temperature seems to be involved in their action (Marinova and Yanishlieva, 1992). As an example, Figure 1 shows the different behavior of tocopherols, depending on the temperature, in conventional high linoleic and genetically modified high oleic sunflower oils, i.e., oils with similar tocopherol compositions but differing in the composition of triacylglycerols. Figure $1 \mathrm{~A}$ shows the formation of polar compounds in the sunflower oils with and without their natural tocopherols heated at $180^{\circ} \mathrm{C}$ for 10 hours (surface-to-volume ratio was 0.4 ), as well as the parallel loss of tocopherols when they were present in the samples (Barrera Arellano et al., 2002). As it can be observed, similar levels of tocopherols were present in both oils, with more than $95 \%$ being $\alpha$-tocopherol. The action of the natural antioxidants is clearly demonstrated by the higher levels of polar compounds of the stripped oils at any heating period. However, the effect of tocopherols in delaying the formation of polar compounds was similar regardless of the degree of oil unsaturation. Figure $1 \mathrm{~B}$ and Figure $1 \mathrm{C}$ show the formation of polar compounds and the loss in tocopherols in the same oils at room temperature and at $100^{\circ} \mathrm{C}$ in the conditions of the Rancimat test (Martín Polvillo et al., 2004; Márquez- Ruiz et al., 2008). In both cases, the action of tocopherols was clearly dependent on the degree of unsaturation. It is important to note that apart from the different temperature, the availability of air may also have an important contribution to the results obtained. At frying temperatures there is air limitation, as air solubility decreases with increasing temperature and no bubbling of air was applied. However, at room temperature and at $100^{\circ} \mathrm{C}$ there was no restriction of air.

The most important difference concerns the rapid exhaustion of tocopherols at frying temperatures and particularly in the less unsaturated oil (Yuki and Ishikawa, 1976; Yoshida et al., 1990; Jorge et al., 1996a; 1996b; Simone and Eitenmiller, 1998; Wagner et al., 2001; Barrera Arellano et al., 2002; Mara et al., 2009). Not only was the loss of tocopherols more rapid in the least unsaturated oil, but also tocopherols were exhausted at lower oil degradation. These results
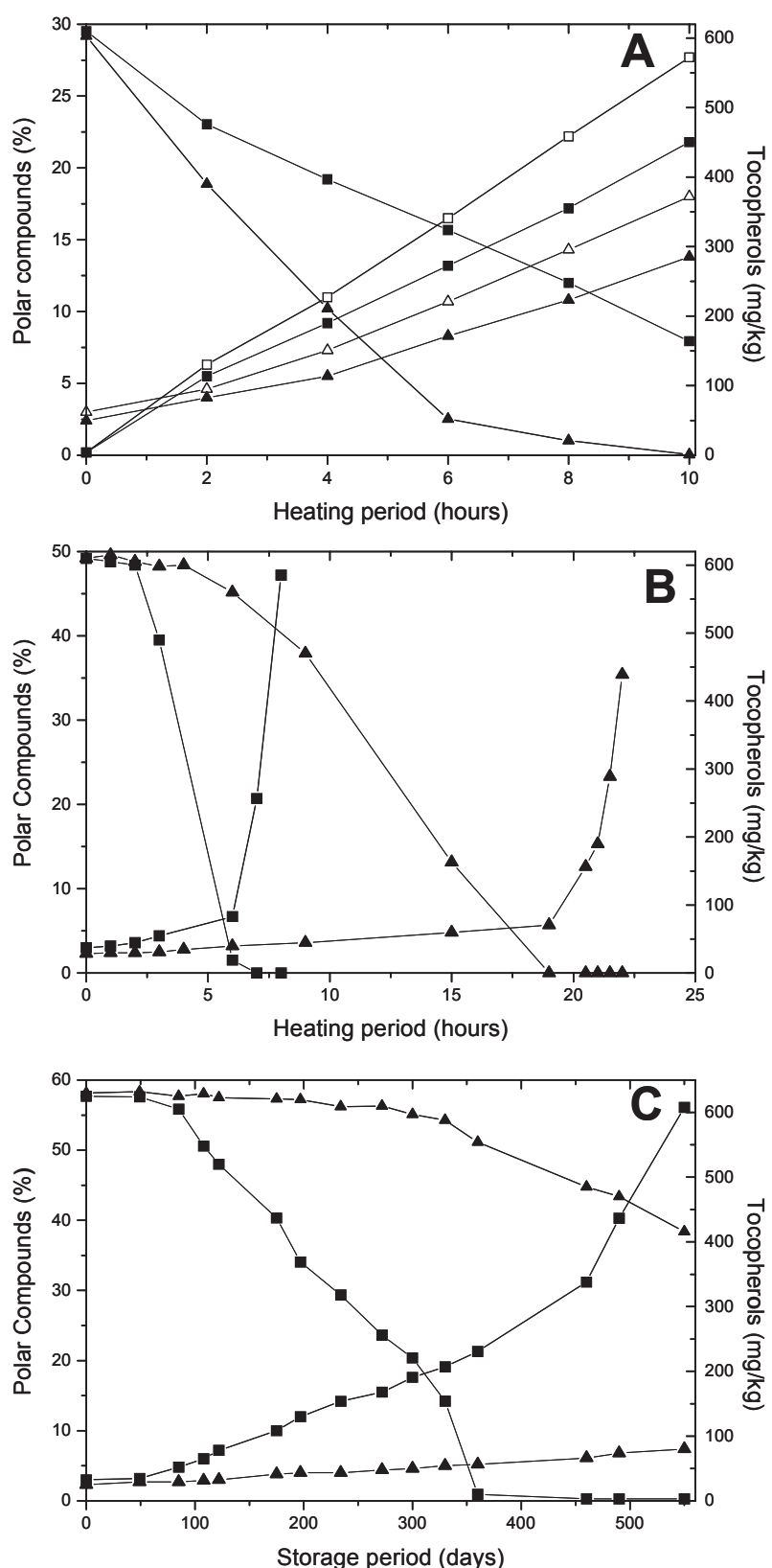

Figure 1

Formation of polar compounds (increasing lines) and loss in natural tocopherols (decreasing lines) in high linoleic ( $\mathbf{})$ and high oleic $(\boldsymbol{\Delta})$ sunflower oils. A) Oils heated at $180^{\circ} \mathrm{C}$-hollow symbols correspond to tocopherol-stripped oils. B) Oils heated at $100^{\circ} \mathrm{C}$ under Rancimat conditions. C) Oils stored at room temperature.

have been reported in different studies either in model systems (Barrera Arellano et al., 1999; Verleyen et al., 2001a) or in oils of different degrees of unsaturation and types of tocopherols (Jorge et al., 1996a, 1996b; Normand et al., 2001; Barrera Arellano et al., 2002; Verleyen et al., 2002).

From these results it is deduced that, on one hand, special attention should be paid to frying operations using monounsaturated oils, as they become unprotected at levels of polar compounds much lower than the limit established in official regulations for discarding fats for human consumption (25 wt \% 
polar compounds). If the fried food has to be stored, oxidation at low temperature would be very rapid in the absence of antioxidants regardless of the degree of unsaturation (Marquez Ruiz et al., 1999). On the other hand, these results indicate that accelerated tests at moderate temperatures or under the conditions of Rancimat tests may be useful to predict the relative shelf-life of different oils and fats but they would not give an indication of their frying performance.

Concerning the type of tocopherols, the relative stability of $\alpha-, \beta-, \gamma$ - and $\delta$-tocopherol at high temperatures has been studied in detail and there is agreement that $\alpha$-tocopherol is less stable than $\delta$-tocopherol, while $\beta$ - and $\gamma$-tocopherols would degrade at intermediate rates (Yoshida et al., 1991a, 1991b, 1992, 1993; Gordon and Kourimska, 1995a; Lampi and Kamal Eldin, 1998; Barrera Arellano et al., 1999, 2002). In this respect, new sunflower lines that contain $\gamma$-tocopherol as the major natural antioxidant instead of $\alpha$-tocopherol, which is characteristic of standard sunflower oil, are of special interest (Demurin et al., 1996; Velasco et al., 2004; Marmesat et al., 2008). The higher protection given by $\gamma$-tocopherol as compared to $\alpha$-tocopherol regardless of the oil used (Lampi and Kamal Eldin, 1998; Barrera Arellano et al., 2002) and the present possibilities of new oils of low degree of unsaturation allow for a foreseeable future when processor needs and consumer demands will be met (Marmesat et al., 2008).

The action of tocotrienols has been less studied. In general, the stability of $\alpha$-tocotrienol was found to be similar to that of $\alpha$-tocopherol both in palm olein and in purified oils containing both antioxidants added (Simone and Eitenmiller, 1998; Wagner et al., 2001; Romero et al., 2004, 2007; Schroeder et al., 2006; Rossi et al., 2007). However, the order of stability of the different tocotrienol homologues was different to that found for their tocopherol counterparts, being $\gamma$-tocotrienol the least stable (Simone and Eitenmiller, 1998; Rossi et al., 2007).

The information on the fate of tocopherols at elevated temperatures is limited, which contrasts with the works on the chemistry of oxidation at room temperature or under the conditions of accelerated test without air limitation. In an excellent review by Kamal-Eldin and Appleqvist (1996) the most significant information on changes at room or moderate temperature can be found in detail.

The formation of new compounds at high temperatures has been studied in model systems (Fujitano and Ando, 1977; Verleyen et al., 2001a 2001b) and in refined oils (Buchowski et al., 1995; Murkovic et al., 1997; Rennick and Warner, 2006). It has been reported that tocopherols have a very low volatility at frying temperature (Pongracz, 1988) and hence, their rapid loss is due to their degradation. Studies on the oxidation products from $\alpha$-tocopherol at 90,180 and $220^{\circ} \mathrm{C}$ report the formation of $\alpha$-tocopherolquinone 2,3-epoxide, $\alpha$-tocopherolquinone 5,6-epoxide and $\alpha$-tocopherolquinone as the major compounds (Murkovic et al., 1997). However, at high temperatures (180 and $\left.220^{\circ} \mathrm{C}\right)$ tocopherols disappear very rapidly (8 hours) and from the two epoxides only the 5,6-epoxide was formed in great amounts, starting to decrease after 5 -hour heating. The time course of $\alpha$-tocopherol thermoxidation shows that $\alpha$-tocopherolquinone was formed at a lower concentration. Similar results have been obtained by Verleyen et al. (2001a; 2001b) in model systems of triolein and tripalmitin mixtures. The formation of $\alpha$-tocopherolquinone has also been recently reported in sunflower and soybean oils heated at $180^{\circ} \mathrm{C}$ with and without $\alpha$-tocopherol added, .although no quinones from $\gamma$ - and $\delta$ - tocopherols were identified in soybean oil (Rennick and Warner, 2006). Surprisingly, with polymerization being the most specific reaction in frying from the first stages of heating, the formation of dimeric and polymeric molecules from tocopherols has been mainly reported at low or moderate temperatures (Kamal-Eldin and Appleqvist, 1996; Gogolewski et al., 2003). Only Fujitani and Ando (1977) reported the formation of two dimers of $\gamma$-tocopherol: 5-( $\gamma$-tocopheroxy) $\gamma$-tocopherol and 5-( $\gamma$-tocopherol-5-yl) $\gamma$-tocopherol) after heating at $180^{\circ} \mathrm{C}$ saturated and unsaturated triglycerides containing $\gamma$-tocopherol.

Although the mechanism of tocopherol degradation at high temperatures is not fully understood, their direct reaction with oxygen has been suggested (Verleyen et al., 2001b). Also, the low amounts found for oxidation compounds of tocopherol with respect to their high loss and their evolution as the heating period increases are indications of the formation of other unknown degradation compounds and also of the further degradation of the initial oxidation compounds formed.

\subsection{Other natural antioxidants}

There are three groups of natural antioxidants whose beneficial action in frying has been consistently reported. These are polyphenols in virgin olive oils, mainly comprised by hydroxytyrosol, tyrosol and their derivatives, and lignans (Bendini et al., 2007; Cicerale et al., 2009); $\gamma$-oryzanol, i.e. sterol esters of ferulic acid, in rice bran oil (Lerma-Garcia et al., 2009); and lignans, mainly sesamine, sesamolin and sesamol, in sesame oil (Moazzami et al., 2007; Namiki, 2007).

The good performance of virgin olive oil in frying as compared to refined olive oil is mainly attributed to the presence of polyphenols. Interestingly, studies analyzing the evolution of tocopherols and polyphenols during frying reported a high rate of degradation for hydroxytyrosol and its derivatives, a similar or lower rate for $\alpha$-tocopherol and a low degradation rate for tyrosol, its derivatives and lignans (Andrikopoulos et al., 2002; Brenes et al., 2002; Gómez-Alonso et al., 2003; Nissiotis and Tasioula-Margari, 2003; Carrasco-Pancorbo et al., 2007; Daskalaki et al., 2009). Therefore, the effective protection found is probably more related to the group of less active antioxidants present, i.e., lignans and tyrosol and their derivatives, which remain longer at frying temperatures.

There have been a limited number of reports on the good frying performance of pure sesame and 
rice bran oil in spite of their wide consumption in populous Asian countries (Valsalan et al, 2004; Krishna et al., 2005). A significant number of recent studies, however, report a significant increase in oil thermostability, as well as a higher retention of natural tocopherols, in the blends of different oils with either sesame or rice bran oil (Chung et al., 2004, 2006; Leonardi 2005; Sharma et al., 2006 Shing et al., 2007: Khan et al., 2008; Farhoosh and Kenary 2009).

Because of the positive effect of lignan compounds and $\gamma$-oryzanol on oil performance, the addition of extracts obtained from sesame and rice bran oils or their by-products to oils of different degrees of unsaturation has been proposed and some ingredients and special oils have been commercialized (Kochhar, 2000; 2001; Gertz, 2004). The addition of these natural products to oils continues to be the subject of many studies, not only focused on the increase in oil thermostability, but also on the retention of compounds of proven health benefits whose intake would increase by means of fried food consumption (Nasirullah and Rangaswamy, 2005; Farag et al., 2007; Hemalatha and Ghafoorunissa, 2007; Lee et al., 2008; Chiou et al., 2009).

Information on the degradation and changes of these groups of compounds of low volatility is very scarce. There are several recent studies on the oxidation products formed from phenolic compounds present in virgin olive oil subjected to oxidation at room or moderate temperatures (Rovellini and Cortesi, 2002; Antolovich et al., 2004; Ríos et al., 2005; Armaforte et al., 2007; Daskalaki et al., 2009). Mass spectra of oxidized compounds from dialdehydic and aldehydic forms of oleuropein and ligstroside aglycons have been reported, although no information on the exact structures an/or their amounts were given. Nevertheless, new compounds formed at frying temperatures from the pool of polyphenols have not been reported until now.

Native sesame oil contains predominantly sesamin and sesamolin and a small amount of sesamol. Neither sesamolin nor sesamin has been found to possess any appreciable antioxidant activity (Budowski, 1964). However, sesamolin may be hydrolyzed during frying, due to the food moisture, giving sesamol and sesaminol (Fukuda et al., 1986; Kochhar, 2001). Both compounds are highly stable and have a synergistic effect with tocopherols, decreasing oil degradation (Yoshida and Takagi, 1999). As for rice bran oil phenolic compounds, information on the expected hydrolysis of $\gamma$-ozyzanol during frying has not been found. On the contrary, it has been reported that the content of oryzanol did not change in practice under usual home frying conditions, regardless of its initial content in the oil (Krishna et al., 2005).

\subsection{Natural plant extracts as oil additives}

In the last decade a significant number of studies focused on the positive effects of the addition of plant extracts, mainly herbs and spices with a double objective. On one hand, plant extracts are used to increase the consumption of natural, healthy compounds in response to consumer demand and, on the other, to delay the oil deterioration by protecting the natural antioxidants.

Extracts of rosemary (Gordon and Kourimska, 1995 a, 1995b; Jaswir and Man 1999; Man and Tan, 1999; Lalas and Dourtoglou, 2003; Kalantzakis and Blekas 2006; Armalo and Jorge, 2008), tea (Naz et al., 2004), sage (Jaswir and Man, 1999; Man and Tan, 1999;), oregano (Houhoula et al., 2003,2004), lavender and thyme (Bensmira et al., 2007), summer savory (Kalantzakis and Blekas, 2006), carob fruit (Bodega et al., 2009), barley seeds (Anwar et al., 2010), Curcuma (Nor et al., 2008a) and others (Shyamala et al., 2005; Nor et al., 2008b) are some examples of the high number of reports on the subject.

In general, the action found is positive because the extracts contain potent antioxidants, which are detailed in an excellent review on the most important herbs and spices (Yanishlieva et al., 2006). However, the effectiveness was similar to that found for synthetic antioxidants, such as BHA and BHT, of low activity (Man and Tan, 1999). In fact, the protective effect during frying is highly variable even for the same extract because of the inherent characteristics of natural products, together with the complexity of the frying process. On one hand, the composition of an extract, normally poorly defined, may be quite different depending on the plant variety, extraction method, solvent used for extraction, concentration added, etc. On the other hand, the antioxidative effect depends on the frying conditions, on the degree of unsaturation of the oil and on the content and chemical structure of other oil minor compounds present exerting a prooxidant or antioxidative action.

\section{SYNTHETIC ANTIOXIDANTS}

The effect of a wide variety of specific compounds in frying has been studied. Among them ascorbyl palmitate and synthetic antioxidants, particularly butylated hydroxytoluene (BHT), butylated hydroxyanisol (BHA), tertiary butyl hydroquinone (TBHQ) and propyl gallate $(P G)$, stand out. The advantage of these studies as compared to those undergone on plant extracts is that the experiments are carried out with individual compounds or combinations of them and thus, the action obtained is directly related to the compound studied.

Ascorbyl palmitate (AP) has been the subject of detailed investigations. In some studies, no significant effect was found with respect to the oil without additives at frying temperature (Augustin et al., 1987; Ibrahim et al., 1991). In other reports, the addition of AP retarded the formation of degradation compounds (Andres, 1984; Gwo et al., 1985; Gordon and Kourimska, 1995b; Satyanarayana et al., 2000; Onal and Ergin, 2002), and increased the stability of tocopherols (Gordon and Kourimska, 1995a), although it was ineffective in protecting fried foods during storage (Masson et al., 2002). 
Synthetic antioxidants are added to fats and oils to effectively extend their shelf life. However, as it occurs with natural tocopherols, the loss in antioxidants under frying conditions was very rapid and their activity was low. In this case, their low effectiveness was attributed not only to their rapid decomposition but also to their volatilization at frying temperature. Thus, when selecting an antioxidant for its use in frying, attention has to be focused on the amount of active antioxidant remaining after frying and protecting the fried foods during storage. This amount will depend on the type of antioxidant and on the level of antioxidant in the frying medium at the time of each frying operation (Augustin and Berry, 1984).

Studies on the fate of synthetic antioxidants have been carried out by controlling the volatiles released from the oil during heating as well as the remaining antioxidants in the oil maintaining their initial structure (Lin et al., 1991; Warner et al., 1986; Dobarganes et al., 1986; Hammama and Nawar, 1991). Thus, the amount of decomposed antioxidant can be calculated by difference (Dobarganes et al., 1986; Hammama and Nawar, 1991). Also, interesting studies have used radioactively labeled antioxidants to obtain appropriate material balances (Lin et al., 1981; Warner et al., 1986). From these studies it is deduced that BHT and TBHQ had the highest volatility, while BHA had intermediate volatility, and propyl galate was the less volatile at frying temperature. With regard to their comparative stability against thermal oxidation the order found was $\mathrm{BHT}>\mathrm{PG}>\mathrm{BHA}>\mathrm{TBHQ}$ (Hammama and Nawar, 1991). However, concerning their effectiveness in decreasing the formation of new compounds during frying, TBHQ has been reported to be much more effective than BHA and BHT (Augustin and Berry, 1984; Gordon and Kourimska, 1995b; Allam and Mohamed, 2002).

The most systematic study has been carried out by Allam and Mohamed (2002) with the aim of clarifying the effect of the most important synthetic antioxidants $\mathrm{BHT}, \mathrm{BHA}, \mathrm{PG}$ and $\mathrm{TBHQ}$ and their binary and tertiary mixtures with synergists and tocopherols. The authors evaluated the loss of the oil stability index of each system in sunflower oil after heating at $180^{\circ} \mathrm{C}$ for one hour. It was observed that the protection at frying temperature was not related to the protection given by the antioxidants at low temperature and it was also concluded that the interaction between antioxidants at high temperature could lead to a negative or positive synergism.

The decomposition products from BHA, BHT, TBHQ and PG at high temperatures have been studied in detail by Hammama and Nawar (1991). $\mathrm{BHT}$ and $\mathrm{PG}$ gave rise to very few decomposition products as compared to BHA and TBHQ. The compounds tentatively identified from $\mathrm{BHA}$ and $\mathrm{BHT}$ were mainly dimeric compounds. From TBHQ, tertiary butyl benzoquinone (TBBQ) was detected as the major degradation product along with many dimerized compounds with ether linkages, some of them with residual antioxidant activity (Kurechi et al., 1983: Kim and Pratt, 1990). Reaction mechanisms explaining the main compounds found from BHA, BHT and TBHQ have been proposed (Hammama and Nawar 1991). Also, dozens of reaction products from $\mathrm{BHA}, \mathrm{BHT}$ and $\mathrm{TBHQ}$ were detected by HPLC on normal phase although the structure of the compounds was not identified (Warner et al., 1986).

Finally, regarding the remaining antioxidant activity of the degradation products from synthetic antioxidants, the low effectiveness of BHT and BHA under frying conditions suggests that their oxidation products has no antioxidant activity even if some of them have been reported as potent antioxidants at room or moderate temperatures (Kurechi and Kato, 1980). However, from TBHQ, TBBQ was detected as a major degradation compound at frying temperature (Kurechi et al., 1983: Kim and Pratt, 1990; Hammama and Nawar 1991) and interestingly, TBHQ was found to be a major degradation product of heated TBBQ. Thus, the rapid degradation of TBHQ would be compatible with an important carrythrough effect attributed to the TBHQ-TBBQ cycling system (Kim and Pratt, 1990). In this respect, novel antioxidants derived from TBHQ but with higher oil solubility, i.e., lauryl TBHQ and lauryl TBBQ, have been found to exert stronger antioxidant activity than TBHQ at temperatures higher than $140^{\circ} \mathrm{C}$ (Zhang et al., 2004).

\section{FINAL REMARKS}

Given the complexity of the frying process and the dependence of the antioxidative effect on the degree of unsaturation of the oil and on the content and chemical structure of other oil minor compounds, attention should be paid to the following points:

1. The action of antioxidants at frying temperature cannot be deduced from their behavior at low or moderate temperatures.

2. There is a rapid loss in antioxidants in oils with high contents of monounsaturated fatty acids and their exhaustion may take place at degradation levels lower than those recommended for discarding the used frying oils. Thus, special attention for maintaining a minimum level of antioxidants in fried products to be stored is necessary.

3. Before the addition of synthetic antioxidants, a rapid test of thermal treatment is recommended to evaluate the performance of the specific type of oil to be used under similar frying conditions.

\section{ACKNOWLEDGMENT}

This work was supported by MICINN (projects AGL 2007-62922 and AGL 2007-63647) and Junta de Andalucía. 


\section{REFERENCES}

Allam SSM, Mohamed HMA. 2002. Thermal stability of some commercial natural and synthetic antioxidants and their mixtures. J. Food Lipids 9, 277-293.

Andres C. 1984. Ascorbic acid ester significantly increases life of frying oil. Food-Processing 45, 22-23.

Andrikopoulos NK, Dedoussis GVZ, Falirea A, Kalogeropoulos N, Hatzinikola HS. 2002. Deterioration of natural antioxidant species of vegetable edible oils during the domestic deep-frying and pan-frying of potatoes. Int. J. Food Sci. Nutr. 53, 351-363.

Antolovich M, Bedgood DR, Bishop AG, Jardine D, Prenzler D, Robards K. 2004. LC-MS investigation of oxidation products of phenolic antioxidants. J. Agric. Food Chem. 52, 962-971.

Anwar F, Qayyum HMA, Hussain Al, lqbal S. 2010. Antioxidant activity of 100 and $80 \%$ methanol extracts from barley seeds (Hordeum vulgare L.): Stabilization of sunflower oil. Grasas y Aceites 61, 237-243.

Armaforte E, Mancebo-Campos V, Bendini A, Salvasor MA, Fregapane G, Carretani L. 2007. Retention effects of oxidized polyphenols during analytical extraction of phenolic compounds of virgin olive oil. J. Sep. Sci. 30, 2401-2406.

Armalo VC, Jorge N. 2008. Acción antioxidante del extracto de romero en el aceite de soja sometido a termoxidación. Grasas y Aceites 59, 128-131.

Augustin MA; Berry SK. 1984. Stability of tapioca chips fried in RBD palm olein trated with antioxidants. $J$. Am. Oil Chem. Soc. 61, 873-877.

Augustin MA; Chua CJ and Heng LK. 1987. Effects of silicone and ascorbyl palmitate on the quality of palm olein used for frying of prawn crackers. J. Sci. Food Agric. 40, 87-93.

Barrera-Arellano D, Ruiz-Méndez MV, Márquez-Ruiz G, Dobarganes MC. 1999. Loss of tocopherols and formation of degradation compounds in triacylglycerol model systems heated at high temperature. J. Sci. Food Agric. 79, 1923-1928.

Barrera-Arellano D, Ruiz-Méndez MV, Velasco J, MárquezRuiz G, Dobarganes MC. 2002. Loss of tocopherols and formation of degradation compounds at frying temperatures in oils differing in unsaturation degree and natural antioxidant content. J. Sci. Food Agric. 82, 16961702.

Bendini A, Cerretani L, Carrasco-Pancorbo A, GomezCaravaca A, Segura-Carretero A, Fernandez-Gutierrez A, Lercker G. 2007. Phenolic molecules in virgin olive oils: a survey of their sensory properties, health effects, antioxidant activity and analytical methods. An overview of the last decade. Molecules 12, 1679-1719.

Bensmira M, Jiang B, Nsabimana C, Jian T. 2007. Effect of lavender and thyme incorporation in sunflower seed oil on its resistance to frying temperatures. Food Res. Int. 40, 341-346.

Bodega DZ, Bastida S, Marmesat S, Pérez-Ollero L, Ruíz-Roso B, Sánchez-Muniz FJ. 2009. Carob fruit poliphenols reduce tocopherol loss, triacylglycerol polymerization and oxidation in heated sunflower oil. J. Am. Oil Chem. Soc. 86, 419-425.

Brenes M, García A, Dobarganes MC, Velasco J, Romero C. 2002. Influence of termal treatments simulating cooking processes on the polyphenol content of virgin olive oil. J. Agric. Food Chem. 50, 5962-5967.

Buchowski M, Nogala-Kalucka M, Gogilewski M. 1995. Changes of tocopherols and phospholipids during heating of low-erucic rapeseed oil at temperature similar to fritting. Fat Sci. Technol. 97, 10-12.
Budowski P. 1964. Recent research on sesamin, sesamolin and related compounds. J. Am. Oil Chem. Soc. 41, 280-285.

Carrasco-Pancorbo A, Cerretani L,Bendini A, SeguraCarretero A, Lecker G, Fernández-Gutiérrez A. 2007. Evaluation of the influence of thermal oxidation and on the antioxidant activity of extravirgin olive oils, $J$. Agric. Food Chem. 55, 4471-4780.

Chiou A, Kalogeropoulos N, Salta FN, Efstathiou P, Andrikopoulos NK. 2009. Pan-frying of French fries in three different edible oils enriched with olive leaf extract: Oxidative stability and fate of microconstituents. LWTFood Sci. Technol. 42, 1090-1097.

Chung J, Lee Y, Choe E. 2004. Effects of sesame oil addition to soybean oil during frying on the lipid oxidative stability and antioxidants contents of the fried products during storage in the dark. J. Food Sci. 769, C574-C578.

Chung J, Lee Y. Choe E. 2006. Oxidative stability of soybean and sesame oil mixtures during frying of flour dough. J. Food Sci. 71, C222-C226.

Cicerale S, Conlan XA, Sinclair AJ, Keast RSJ. 2009. Chemistry and health of olive oil phenolics. Crit. Rev. Food Sci. Nutr. 49, 218-236.

Daskalaki D, Kefi G, Kotsiou K, Tasioula-Margari M. 2009. Evaluation of phenolic compound degradation in virgin olive oil during storage and heating. J. Food Nutr. Res. 48, 31-41.

Demurin Y, Škorić D, Karlovic D. 1996. Genetic variability of tocopherol composition in sunflower seeds as a basis of breeding for improved oil quality. Plant Breed. 115, 33-36.

Dobarganes MC, Márquez Ruíz G. 2007. Formation and analysis of oxidized monomeric, dimeric and higher oligomeric triglycerides, in Erickson MD (Ed.), Deep Frying: Chemistry Nutrition and Practical Applications. $2^{\text {nd }}$ edition, Champaign, Illinois, AOCS, 87-110.

Dobarganes MC, Pérez-Camino MC, Gutierrez Rosales F. 1986. Acción protectora de los antioxidantes BHT y $\mathrm{BHA}$ en grasas calentadas a elevada temperatura. Grasas y Aceites 37, 262-266.

Dobarganes MC. 1998. Formation and analysis of high molecular-weight compounds in frying fats and oil. OCL, 5, 41-47.

Farag RS, Mahmoud EA, Basuni AM. 2007. Use crude olive leaf juice as a natural antioxidant for the stability of sunflower oil during heating. Int. J. Food Sci. Technol. 42, 107-115.

Farhoosh R, Kenary RE. 2009. Anti-rancidity effects of sesame and rice bran oils on canola oil during deep frying. J. Am. Oil Chem. Soc. 86, 539-544.

Fujitani T, Ando H. 1977. Oxidative dimerization of tocopherols during the course of thermal oxidation of saturated and unsaturated triglycerides. J. Japan Oil Chem. Soc. 26, 768-773.

Fukuda $Y$, Isobe M, Nagata M, Osawa T, Namiki M. 1986. Acidic transformation of sesamolin, the sesame oil constituent, into an antioxidant bisepoxilignan, sesaminol. Heterocycles 24, 923-926.

Gertz C. 2004. Optimising the baking and frying process using oil-improving agents. Eur. J. Lipid Sci. Technol. 106, 736-745.

Gogolewski M, Nogala-Kalucka M, Galuba G. 2003. Studies on dimerisation of tocopherols under the influence of methyl linoleate peroxides. Nahrung/Food 47, 74-78

Gomez-Alonso S, Fregapane G, Salvador MD, Gordon $\mathrm{MH}$. 2003. Changes in phenolic composition and antioxidant activity of virgin olive oil during frying. $J$. Agr. Food Chem. 51, 667-672. 
Gordon MH, Kourimska L. 1995a. Effect of antioxidants on losses of tocopherols during deep-fat frying. Food Chem. 52, 175-177.

Gordon MH, Kourimska L. 1995b. The effects of antioxidants on changes in oils during heating and deep frying. J. Sci. Food Agric. 68, 347-353.

Gwo YY, Flick GJ, Dupuy H, Ory RL, Baran WL. 1985. Effect of ascorbyl palmitate on the quality of frying fats for deep frying operations. J. Am. Oil Chem. Soc. 62, 1666-1671.

Hammama AA, Nawar WW. 1991. Thermal decomposition of some phenolic antioxidants. J. Agric. Food Chem. 39, 1063-1069.

Hemalatha S, Ghafoorunissa. 2007. Sesame lignans enhance the thermal stability of edible vegetable oils. Food Chem. 105, 1076-1085.

Houhoula DP, Oreopoulou V, Tzia C. 2003. Antioxidant efficiency of oregano during frying and storage of potato chips. J. Sci. Food Agric. 83, 1499-1503.

Houhoula DP, Oreopoulou V, Tzia C. 2004. Antioxidant efficiency of oregano in frying and storage of fried products. Eur. J. Lipid Sci. Technol. 106, 746-751.

Ibrahim K, Augustin MA, Ong ASH. 1991. Effects of ascorbyl palmitate and silicone on frying performance of palm olein. Pertanika 14, 53-57.

Jaswir I, Man YBC. 1999. Use optimization of natural antioxidants in refined, bleached, and deodorized palm olein during repeated deep-fat frying using response surface methodology. J. Am. Oil Chem. Soc. 76, 341-348.

Jorge N, Márquez-Ruiz G, Martín-Polvillo M, RuizMéndez MV, Dobarganes MC. 1996a. Influence of dimethylpolysiloxane addtion to edible oils: dependance on the main variables of the frying process. Grasas $y$ Aceites 47, 14-19.

Jorge N, Márquez-Ruiz G, Martín-Polvillo M, RuizMéndez MV, Dobarganes MC. 1996b. Influence dimethylpolyxilosane addition to frying oils: Performance of sunflower oils in discontinuous and continuous laboratory frying. Grasas y Aceites 47, 20-25.

Kalantzakis G, Blekas G. 2006. Effects of Greek sage and summer savory extracts on vegetable oil thermal stability. Eur. J. Lipid Sci. Technol. 108, 842-847.

Kamal-Eldin A, Appleqvist LA. 1996. The chemistry and antioxidant properties of tocopherols and tocotrienols. Lipids 31, 671-699.

Khan MI, Asha MR, Bhat KK, Khatoo S. 2008. Studies on quality of coconut oils blends after frying potato chips. J. Am. Oil Chem. Soc. 85, 1165-1172.

Kim CM, Pratt DE. 1990. Degradation products of 2-tertbutylhydroquinone at frying temperature. J. Food Sci. 55, 847-853.

Kochhar SP. 2000. Stabilization of frying oils with natural antioxidative components. Eur. J. Lipid Sci. Technol. 102, 552-559.

Kochhar SP. 2001. The composition of frying oils. In Rossell JB (Ed.), Frying. Improving Quality, Lancaster, Woodhead, 87-114.

Krishna AGG, Khatoon S, Babylatha R. 2005. Frying performance of processed rice bran oils. J. Food Lipids, 12, 1-11.

Kurechi T, Aizawa M, Kunugi A. 1983. Studies on the antioxidants. XVIII. Oxidation products tertiary butyl hydroquinone (TBHQ). J. Am. Oil Chem. Soc. 60, 1878-1882.

Kurechi T, Kato T. 1980. Studies on the antioxidants. XI. Oxidation products of concomitantly butylated hydroxyanisole and butylated hydroxytoluene. J. Am. Oil Chem. Soc. 57, 220-223.
Lalas S, Dourtoglou V. 2003. Use of rosemary extract in preventing oxidation during deep-fat frying of potato chips. J. Am. Oil Chem. Soc. 80, 579-583.

Lampi A, Kamal-Eldin A. 1998. Effect of $\alpha$ - and $\gamma$ tocopherols on thermal polymerization of purified higholeic sunflower triacylglycerols. J. Am. Oil Chem. Soc. 75, 1699-1703.

Lee J, Lee Y, Choe E. 2008. Effect of sesamol, sesamin and sesamolin extracted from roasted sesame oil on the thermal oxidation of methyl linoleate. LWT-Food Sci. Technol. 41, 1871-1875.

Leonardi M. 2005. New blends of frying vegetable oils. Riv. Ital. Sost. Grasse 82, 71-81.

Lerma-Garcia MJ, Herrero-Martinez JM, Simo-Alfonso EF, Mendonca CRB, Ramis-Ramos G. 2009. Composition, industrial processing and applications of rice bran gamma-oryzanol. Food Chem. 115, 389-404.

Lin FS, Warner CR, Fazio T. 1981. Alteration of phenolic antioxidants in heated vegetable oils. J. Am. Oil Chem. Soc. 58, 789-791.

Man YBC, Tan CP. 1999. Effect of natural and synthetic antioxidants in refined, bleached, and deodorized palm olein during repeated deep-fat frying of potato chips. J. Am. Oil Chem. Soc. 76, 331-339.

Mara MS, Corsini S, Silva MG, Jorge N. 2009. Loss in tocopherols and oxidative stability during the frying of frozen cassava chips. Grasas y Aceites 60, 77-81.

Marinova EM, Yanishlieva NV. 1992. Effect of temperature on the antioxidative action of inhibitors in lipid autoxidation. J. Sci. Food Agric. 60, 313-318.

Marmesat S, Velasco L, Ruiz-Méndez MV, FernándezMartínez JM, Dobarganes MC. 2008. Thermostability of genetically modified sunflower oils differing in fatty acid and tocopherol compositions. Eur. J. Lipid Sci. Technol. 110, 776-782.

Márquez-Ruiz G, Martín-Polvillo $\mathrm{M}$, Jorge N, Ruiz Méndez MV, Dobarganes MC. 1999. Influence of used frying oil quality and natural tocopherol content on oxidative stability of fried potatoes. J. Am. Oil Chem. Soc, 76, 421-425.

Márquez-Ruiz G, Martín-Polvillo M, Velasco J, Dobarganes M.C. 2008. Formation of oxidation compounds in olive and sunflower oils under oxidative stability index (OSI) conditions. Eur. J. Lipid Sci. Technol. 110, 465-471.

Martín Polvillo M, Márquez-Ruiz G, Dobarganes MC. 2004. Oxidative stability of sunflower oils differing in unsaturation degree during long-term storage at room temperature. J. Am. Oil Chem. Soc. 81, 577-583.

Masson L, Robert P, Dobarganes MC, Urra C, Romero N, Ortiz J, Goicoechea E, Pérez P, Salamé M, Torres R. 2002. Stability of potato chips fried in vegetable oils with different degree of unsaturation. Effect of ascorbyl palmitate during storage. Grasas y Aceites 53, 190-198.

Moazzami AA, Haese S L, Kamal-Eldin A. 2007. Lignan contents in sesame seeds and products. Eur. J. Lipid Sci. Technol. 109, 1022-1027.

Murkovic M, Wiltschko B, Pfannhauser W. 1997. Formation of alpha-tocopherolquinone and alphatocopherolquinone epoxides in plant oil. Fett-Lipid 99, 165-169

Namiki M. 2007. Nutraceutical functions of sesame. A review. Crit. Rev. Food Sci. Technol. 47, 651-673.

Nasirullah, Rangaswamy BL. 2005. Oxidative stability of healthful frying oil medim and uptake of inherent nutraceuticals during deep frying. J. Am. Oil Chem. Soc. 82, 753-757. 
Naz S, Sheikh H, Siddiqi R, Sayeed SA. 2004. Oxidative stability of olive, corn and soybean oil under different conditions. Food Chem. 88, 253-259.

Nissiotis M, Tasioula-Margari M. 2003. Changes in antioxidant concentration of virgin olive oil during thermal oxidation. Food Chem. 77, 371-376.

Nor FM, Mohamed S, Idris NA, Ismail R. 2008a. Antioxidative properties of Curcuma Longa leaf extracts in accelerated oxidation and deep frying studies. J. Am. Oil Chem. Soc. 86, 141-147.

Nor FM, Mohamed S, Idris NA, Ismail R. 2008b. Antioxidative properties of Pandanus amaryllifolius leaf extracts in accelerated oxidation and deep frying studies. Food Chem.110, 319-327.

Normand L, Eskin NAM, Przybyslki R. 2001. Comparison of the stability of regular and and high-oleic sunflower oils. J. Am. Oil Chem. Soc. 84, 331-334.

Onal B, Ergin G. 2002. Antioxidative effects of alphatocopherol and ascorbyl palmitate on thermal oxidation of canola oil. Nahrung 46, 420-426.

Pongracz VG. 1988. Hitzestabilität der tocopherole. Fat Sci. Technol. 90, 247-251.

Rennick KA, Warner K. 2006. Effect of elevated temperatures on the formation of tocopherolquinones in oils. J. Agric. Food Chem. 54, 2188-2192.

Ríos JJ, Gil MJ, Gutiérrez-Rosales F. 2005. Solidphase extraction gas chromatography- ion trap-mass spectrometry qualitative method for evaluation of phenolic compounds in virgin olive oil and structural confirmation of oleuropein and ligstroside aglycons and their oxidation products. J. Chromatogr. A, 1093, 167-176.

Romero N, Robert P, Masson L, Ortiz J, González K, Tapia K, Dobarganes M.C. 2007. Effect of $\alpha$-tocopherol, $\alpha$-tocotrienol and Rosa mosqueta shell extract on the performance of antioxidant-stripped canola oil (brassica sp) at high temperature. Food Chem. 104, 383-389.

Romero N, Robert P, Masson L, Ortiz J, Pavez J, Garrido C, Foster M, Dobarganes MC. 2004. Effect of $\alpha$-Tocopherol and $\alpha$-Tocotrienol on the performance of Chilean Hazelnut Oil (Gevuina avellana mol) at high temperature. J. Sci. Food Agric. 84, 943-948.

Rossi M, Alamprese C, Ratti S. 2007. Tocopherols and tocotrienols as free radical-scavengers in refined vegetable oils and their stability during deep-fat frying'. Food Chem. 102, 812-817.

Rovellini P, Cortesi N. 2002. Liquid chromatographymass spectrometry in the study of oleuropein and ligstroside aglycons in virgin olive oil: aldehydic, dialdehydic forms and their oxidized products. Riv. Ital. Sost. Grasse 79, 1-14.

Satyanarayana A, Giridhar N, Joshi GJ, Rao DG. 2000 Ascorbyl palmitate as an antioxidant for deep fat frying of potato chips in peanut oil. J. Food Lipids 7, 1-10.

Schroeder MT, Becker EM, Skibsted MH. 2006. Molecular mechanism of antioxidant synergism of tocotrienols and carotenoids in palm oil. J. Agric. Food Chem. 54, 3445-3453.

Sharma HK, Kaur B, Sarkar BC, Singh C. 2006. Thermal behaviour of pure rice bran oil, sunflower oil and their model blends during deep fat frying. Grasas y Aceites 57, 376-381.

Shing A, Sharme HK, Sarkar BC, Singh C and Shitandi AA. 2007. Thermal behaviour of pure rice bran oil, safflower oil and their model blends during deep fat frying. J. Food Sci. Technol. 44, 52-55.
Shyamala BN, Gupta S, Lakshmi AJ, Prakash J. 2005. Leafy vegetable extracts. Antioxidant activity and effect on storage stability of heated oils. Int. Food Sci. Emerg. Technol. 6, 239-245.

Simone AH, Eitenmiller RR. 1998. Retention of Vitamin E and added retinyl palmitate in selected vegetable oils during deep-fat frying and in fried breaded products. J. Agric. Food Chem. 46, 5273-5277.

Valsalan A, Siddhu A, Sundararaj P. 2004. Assessment of rice bran oil as a cooking medium. J. Food Sci. Technol. 41, 248-255.

Velasco L, Domínguez J, Fernández-Martínez JM. 2004. Registration of T589 and T2100 sunflower germplasms with modified tocopherol profiles. Crop Sci. 44, 361-362.

Verleyen T, Kamal-Eldin A, Dobarganes MC, Verhe R, Dewettinck K, Huyghebaert A. 2001a. Modeling of $\alpha$-tocopherol loss and oxidation products formed during thermoxidation in triolein and tripalmitin mixtures. Lipids 36, 719-726.

Verleyen T, Kamal-Eldin A, Mozutaityte R, Verhe R, Dewettinck K, Huyghebaert A, de Greyt W .2002. Oxidation at elevated temperatures: competition between $\alpha$-tocopherol and unsaturated triacylglycerols. Eur. J. Lipid Sci. Technol. 104, 228-233.

Verleyen T, Verhe R, Huyghebaert A, Dewettinck K, de Greyt W. 2001b. Identification of $\alpha$-tocopherol oxidation products in triolein at elevated temperatures. J. Agric. Food Chem. 49, 1508-1511

Wagner KH, Wotruba F, Elmadfa I. 2001. Antioxidative potencial of tocotrienols and tocopherols in coconut fat at different oxidation temperatures. Eur. J. Lipid Sci. Technol. 103, 746-751.

Warner CR, Daniels HD, Lin FSD, Joe FL, Fazio T. 1986. Fate of antioxidants and antioxidant-derived products in deep fat frying and cookie baking. J. Agr. Food Chem. 34, 1-5.

Yanishlieva NV, Marinova E, Pokorny J. 2006. Natural antioxidants from herbs and spices. Eur. J. Lipid Sci. Technol. 108, 776-793.

Yoshida H, Hirooka N, Kajimoto G. 1990. Microwave energy effects on quality of some seed oils. J. Food Sci. 55, 1412-1416.

Yoshida H, Hirooka N, Kajimoto G. 1991b. Microwave heating effects on relative stabilities of tocopherols in oils. J. Am. Oil Chem. Soc. 56, 1042-1046.

Yoshida H, Kajimoto G, Emura S. 1993. Antioxidant effects of d-tocopherols at different concentrations in oils during microwave heating. J. Am. Oil Chem. Soc. 70, 989-995.

Yoshida H, Takagi S. 1999. Antioxidative effects of sesamol and tocopherols at various concentrations in oils during microwave heating. J. Sci. Food Agric. 79, 220-226.

Yoshida H, Tatsumi M, Kajimoto G. 1991a. Relationship between oxidative stability of vitamin $\mathrm{E}$ and production of fatty acids in oils during microwave heating. J. Am. Oil Chem. Soc. 68, 566-570.

Yoshida H, Tatsumi M, Kajimoto G. 1992. Influence of fatty acids on the tocopherol stability in vegetable oils during microwave heating. J. Am. Oil Chem. Soc. 69, 119-125.

Yuki E, Ishikawa Y. 1976. Tocopherol contents of nine vegetable frying oils, and their changes under simulated deep-fat frying conditions. J. Am. Oil Chem. Soc. 53, 673-676.

Zhang CX, Wu H, Weng XC. 2004. Two novel synthetic antioxidants for deep frying oils. Food Chem. 84, 219-222.

Recibido: $10 / 2 / 10$

Aceptado: 14/4/10 